\title{
Correlating the depth of invasion at specific anatomical locations with the risk for regional metastatic disease to lymph nodes in the neck for oral squamous cell carcinoma
}

\author{
Hans C. Brockhoff II, DDS, MD \\ Fellow Oncology/Microvascular Surgery \\ Oral \& Maxillofacial Surgery \\ University of Michigan \\ Address: Oral and Maxillofacial Surgery \\ University of Michigan \\ Department of Surgery \\ 1500 E. Medical Center Dr. \\ Ann Arbor, MI 48109 \\ E-mail: hans.brockhoff@gmail.com
Roderick Y. Kim DDS, MD
Resident
Oral \& Maxillofacial Surgery
University of Michigan \\ Thomas M. Braun, PhD \\ Professor \\ Department of Biostatistics \\ University of Michigan School of Public Health
}

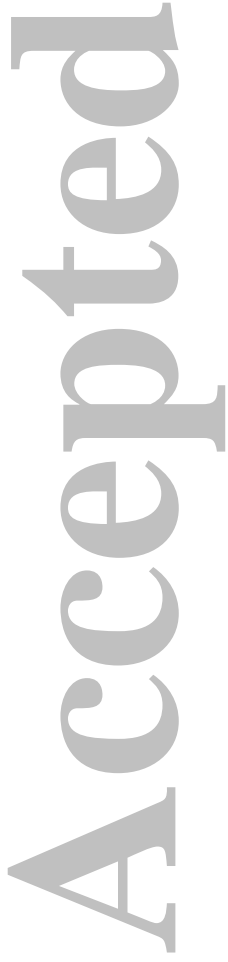

\author{
Christos Skouteris, DMD, PhD \\ Clinical Assistant Professor \\ Oral \& Maxillofacial Surgery \\ University of Michigan \\ Joseph I. Helman, DMD \\ Professor \\ Oral \& Maxillofacial Surgery \\ University of Michigan
}

Brent B. Ward DDS, MD

Associate Professor \& Chair

Fellowship Program Director

University of Michigan

This is the author manuscript accepted for publication and has undergone full peer review but has not been through the copyediting, typesetting, pagination and proofreading process, which may lead to differences between this version and the Version record. Please cite this article as doi:10.1002/ hed.24724. 


\begin{abstract}
The aim of this study was to investigate the critical primary tumor depth of invasion in oral squamous cell carcinoma that would lead to a $20 \%$ or greater risk of nodal metastasis.
\end{abstract}

Methods: An IRB approved retrospective review of our head and neck database was performed from 2009-2014 and the data was statistically analyzed.

$\underline{\text { Results: }} 286$ patients with a diagnosis of oral squamous cell carcinoma that met our inclusion criteria underwent primary excision and neck dissection. For a depth of invasion of $1 \mathrm{~mm}$ or less, there were no patients with a positive node. From 1.1-2mm of depth of invasion there was $1 / 11(9 \%)$ patients who had at least one positive node. At

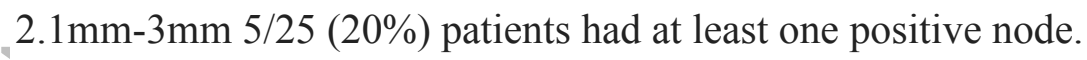

Conclusion: Depth of invasion and the location of the tumor are two important variables to consider when making treatment recommendations to patients with clinical N0 disease.

John Wiley \& Sons, Inc. 


\title{
Correlating the depth of invasion at specific anatomical locations with the risk for regional metastatic disease to lymph nodes in the neck for oral squamous cell carcinoma
}

\author{
Hans C Brockhoff II \\ Roderick Y Kim \\ Thomas M. Braun \\ Christos Skouteris \\ Joseph I. Helman \\ Brent B. Ward
}

Introduction: An estimated 45,780 new cases and 8,650 deaths due to oral cavity and oropharynx cancers are expected in the United States during 2015. ${ }^{1}$ The 5 - and 10-year relative survival rates are $63 \%$ and $51 \%$, respectively. ${ }^{1}$ Regional Metastatic disease to the lymph nodes remains an important clinical prognostic factor.

Decision making in regards to management of the neck has generated a tremendous amount of investigation and effort. Even with the aid of multiple imaging modalities, the detection of early microscopic disease to the lymph nodes remains difficult. When considering all stages of oral squamous cell carcinoma, occult nodal metastasis has been reported in up to $50 \%$ of cases. ${ }^{2-3}$ Additionally, it is clear that not every patient, more specifically the clinically N0 neck, carries the same risk for nodal metastasis, and thus it would not be reasonable to consider every patient for an elective neck dissection due to the morbidity associated with the procedure ${ }^{4-5} \mathrm{~A}$ neck dissection is generally offered to those patients who harbor at least a $20 \%$ risk for occult nodal metastasis. ${ }^{6}$

Investigations of the histopathological features of oral squamous cell carcinoma are numerous in order to help better characterize which patient's pose the greatest risk 
for harboring occult disease. ${ }^{7-15}$ One of the more recognized indicators of placing a patient at risk for lymph node metastasis is the depth of tumor invasion. Kane et al reviewed 48 previously untreated patients with a T1/T2 N0 squamous carcinoma of the oral cavity who underwent a primary excision of the tumor and elective neck node dissection and concluded that depth of invasion was the most significant histologic predictor of subclinical node metastasis. ${ }^{12}$ Discovering what the precise value for the depth of invasion that would substantiate an elective neck dissection has continued to be a point of debate. Authors have advocated for various depths of thicknesses as a predictor, and current studies give a wide range from $2 \mathrm{~mm}$ to greater than $5 \mathrm{~mm} \cdot{ }^{10-15}$ Warburton et al reported in 29 patients with T1NOM0 or T2NOMO oral squamous cell carcinoma of the tongue or floor of mouth that on statistical analysis that a tumor thickness of $2.2 \mathrm{~mm}$ is the optimal cutoff point with a statistically significant association with delayed neck metastasis. ${ }^{14}$ Huang et al performed a meta-analysis involving 16 studies yielding a pooled total of 1136 patients. They looked at tumor thickness and it's predictive value for cervical lymph-node involvement. Their conclusion was that tumor thickness was indeed a strong predictor for cervical lymph-node involvement and that the optimal cutoff point was $4 \mathrm{~mm} \cdot{ }^{24}$

Within the current literature, there is still a wide range of variability and conflicting data, which has led to the lack of consensus in regards to the depth of invasion. Many of the studies are small in size, which further add to the challenge. The purpose of this study is to review the experience at our institution and investigate 
what the critical depth of invasion would be, leading to a $20 \%$ or greater risk of nodal metastasis.

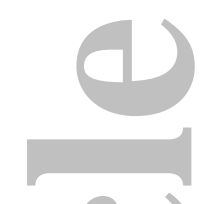

Materials and Methods: We completed an institutional review board (IRB) approved, retrospective, single institution review of all patients from 2009-2014. Our institutional review board consists of an established committee that reviews and approves research involving human subjects. This ensures that all human subject research is conducted in accordance with federal, institutional, and ethical guidelines. Our inclusion criteria consisted of all patients who had received any form of neck dissection with resection of a primary oral cavity squamous cell carcinoma completed by one of our four attending oral/head and neck surgeons. Patients were excluded from our study if they had previously been treated with a neck dissection, previous resection of an oral cancer, previous treatment with radiation and/or chemotherapy specifically for head and neck cancer. The data collected included: age, gender, race, pathologic staging (TNM classification), location of primary tumor, depth of invasion, type of surgery performed, and presence of lymph node involvement.

The information regarding tumor characteristics including depth of invasion was obtained from pathology reports of the final specimen. At our institution measured depths of invasion are standardized and read as the depth tumor that extends vertically beyond the basement membrane into the underlying tissue not the total tumor 
thickness.

Descriptive statistics were used to summarize the clinical characteristics of the sample of patients. The strength of the association of tumor size and depth of invasion with node positivity was assessed using logistic regression. The diagnostic ability of depth of invasion for nodal involvement was also summarized with empirical estimates of sensitivity, specificity, positive predictive value (PPV), negative predictive value (NPV), and area under the curve (AUC); the bootstrap was used to compute $95 \%$ confidence intervals for those quantities.

Results: Over a period of six years, a total of 303 patients with a diagnosis of oral squamous cell carcinoma in need of a primary excision and neck dissection presented to our institution at the University of Michigan. Of these patients 286 met both our criteria and thus were analyzed. 169 (59\%) were male and 117 (41\%) were female with average age at the time of surgery being $63(+/-12.5)$ years range of 18 to 95 years. The majority of patients, 270 (94\%), were Caucasian.

\section{Location}

The number of tumors presenting in anatomic location were as follows: oral tongue 105 (37\%), alveolus/hard palate 91 (32\%), floor of mouth 39 (14\%), retromolar trigone $25(9 \%)$, and other $24(8 \%)$ 


\section{Pathologic staging}

There were 66 (23\%) with stage I disease, 54 (19\%) with stage II, 39 (14\%) with stage III, and 127 (44\%) with stage IV. The average size of the tumor was $2.7 \mathrm{~cm}$ $(\mathrm{SD}+/-1.1)$ with a range $0.1 \mathrm{~cm}-6.9 \mathrm{~cm}$. (Table 1)

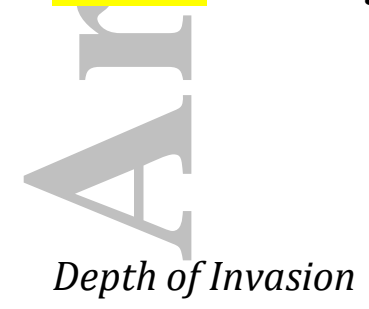

Table 1: Pathologic staging (No. of patients=286)

$115(40 \%)$ patients had at least one positive lymph node on the final pathology report, while $171(60 \%)$ were negative.

\section{Association of tumor size and depth of invasion with node positivity}

Three logistic regression models were created, one with size of tumor predicting node positivity (Model A), one with depth of invasion predicting node positivity (Model B), and one with both size of tumor and depth of invasion predicting node positivity (Model C). In Model A, size of tumor was significantly associated with node positivity (odds ratio $=1.9 ; p$-value $<0.001$ ). In Model $\mathrm{B}$, depth of invasion was significantly associated with node positivity (odds ratio $=1.3 ; p$-value $=0.002$ ). In Model C, only depth of invasion is statistically significant $(\mathrm{p}<0.001)$. Thus, although both size of tumor and depth of invasion were associated with node positivity, depth 
of invasion was a stronger predictor and remained significant after controlling for tumor size, while the converse was not true.

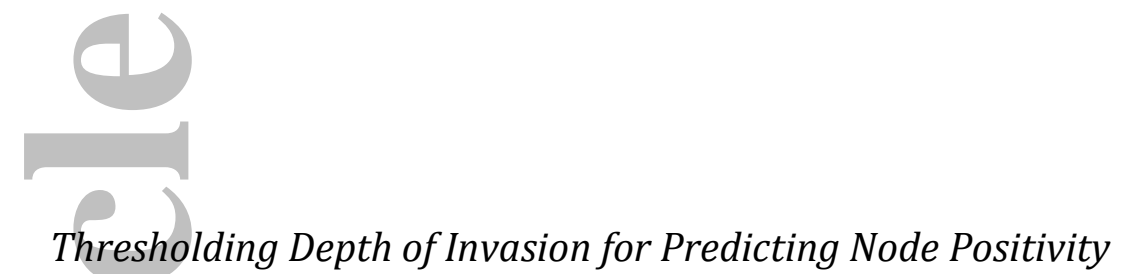

Table 2 displays the percentage of necks with positive nodes measured at $1 \mathrm{~mm}$ increments of depth of invasion. Each neck was individually assessed such that amongst our 286 patients, we found that there were a total of 390 neck specimens (104 patients required a bilateral neck dissection). At $1 \mathrm{~mm}$ depth of invasion we found that there were 7 necks in our data set and none of them had a positive node. At $2 \mathrm{~mm}$ depth of invasion, there were 12 patients with negative node necks and 3 with positive for an overall percentage of $20 \%$. Increasing depth of invasion beyond $2 \mathrm{~mm}$ consistently demonstrated a greater than $20 \%$ node positivity rate reaching a rate higher than $50 \%$ at $10 \mathrm{~mm}$.

\section{TABLE 2: Percentage of necks with positive nodes measured at $1 \mathrm{~mm}$ increments of depth of invasion}

This same methodology was applied to various anatomical sites. Only those anatomical sites for which we had sufficient data to make statistical inference were included in this analysis. Table 3 shows the first recorded depth of invasion (the shallowest depth) where at least $20 \%$ of the necks had positive lymph nodes on final pathology report. 
TABLE 3: Various anatomical sites showing the shallowest depth of invasion where at least $20 \%$ of the necks had positive lymph nodes

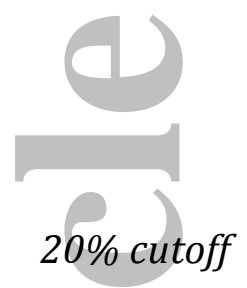

Table 4 displays what we called our $20 \%$ cutoff point. This descriptive data ide identifies the precise value for the depth of invasion where $20 \%$ of all patients at that depth and shallower would present with positive lymph nodes. We found this point to be significant at $4 \mathrm{~mm}$. In other words, at $4 \mathrm{~mm}$ depth of invasion, we know that the collective sum of patients with $1 \mathrm{~mm}, 2 \mathrm{~mm}, 3 \mathrm{~mm}$, and $4 \mathrm{~mm}$ depth of invasion there is a $22 \%$ incidence of positive disease in the neck. This analysis differs from the data presented in Table 2 which looked at node positive at isolated depths.

Table 4: $20 \%$ cutoff points where $20 \%$ of all necks at that depth and shallower would present with positive nodes

This same methodology was applied to various anatomical sites. Only those anatomical sites for which we had sufficient data to make statistical inference were included. Table 5 shows the cutoff points where $20 \%$ of all patients at that depth and shallower would present with positive lymph nodes. The tongue was $2 \mathrm{~mm}$, the floor of mouth was $3 \mathrm{~mm}$, the retromolar trigone was $4 \mathrm{~mm}$, and the alveolus/hard palate was $4 \mathrm{~mm}$. 
Table 5: 20\% cutoff points for various anatomical sites with 95\% confidence intervals among all sites

\section{Diagnostic operating characteristics of depth of invasion}

The diagnostic operating characteristics of depth of invasion (mm) for predicting nodal involvement are listed in Table 6. In our analysis, we focused on the negative predictive value (NPV) at the various depths representing patient whom if a neck dissection was not performed, would truly be negative for disease. In this analysis at $4 \mathrm{~mm}$ depth of invasion, $80 \%$ of patients would not have received a neck dissection and would be negative for disease, which means that only $20 \%$ of patients who did not receive a neck dissection would be positive for disease. Thus, $4 \mathrm{~mm}$ was the critical value in this analysis.

Table 6: Diagnostic operating characteristics of depth of invasion ( $\mathrm{mm}$ ) for predicting nodal involvement

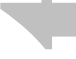

This same methodology was applied to various anatomical sites. Only those anatomical sites for which we had sufficient data to make statistical inference were included. Table 7 shows the critical values for depth of invasion where the negative predictive values (NPV) were $80 \%$ or greater. This translates to the depth of invasion where if a patient did not receive a neck dissection, then only less than or equal to $20 \%$ of patients would be harboring nodal disease.

Table 7: Negative predictive values (NPV) at various anatomical sites predicting a $20 \%$ nodal involvement 


\section{(1)}

In our final analysis (Table 8) we looked only at T1 lesions since T2 have historically undergone neck dissection in general. There were a total of 111 necks analyzed from our data. At $2 \mathrm{~mm}$ depth of invasion, the descriptive data yielded $30 \%$ of patients had positive lymph nodes, the negative predictive value was $80 \%$, and the $20 \%$ cutoff point resided there as well. Therefore, the descriptive data, NPV, and $20 \%$ cutoff point all indicate that a neck dissection should be performed at $2 \mathrm{~mm}$ if the surgeon accepts a $20 \%$ risk for occult nodal metastasis.

\section{Table 8: T1 Lesions (No. of necks=111)}

\section{Discussion:}

Performing a neck dissection will ultimately enable correct staging of the patient, lend insight into prognosis, and aid in determination of adjuvant treatments. Shah et al performed a retrospective review of pathology reports of 501 consecutive 
patients at Memorial Sloan-Kettering Cancer Center (New York) with primary oral cavity squamous cell carcinoma. They found 192 patients were N0 at presentation and underwent an immediate elective radical neck dissection. Clinically occult metastatic disease was present in $34 \%$ of the patients. ${ }^{20} \mathrm{~A}$ more recent study out of that same institution from $1985-2005$ looked at 216 patients with early stage (cT1T2N0) squamous cell carcinoma of the oral tongue. Importantly in their multivariate analysis, the main independent predictor of disease free survival and overall survival was the status of the neck. Those patients who had occult nodal metastasis had a 5-fold increased risk of dying from the disease compared with patients who did not have metastatic disease. Furthermore, in this same study, the incidence of occult nodal metastases was $28 \% .{ }^{21}$ Additionally, Pimenta Amarel et al and Kligerman et al reported an incidence of $23 \%$ and $21 \%$ respectively for occult metastasis in oral squamous cell carcinoma. ${ }^{22,23}$ Despite non-uniformity with decision making in regard to the management of the neck and what the appropriate risk for nodal metastasis warranting a neck dissection, the evidence supporting a value of $20 \%$ has been accepted by many.

Discovering the precise value for depth of invasion that would substantiate the need for an elective neck dissection has continued to be a point of debate. Many studies have advocated for various depths of invasion as a predictor, and current studies give a wide range from $2 \mathrm{~mm}$ to greater than $5 \mathrm{~mm}$. Most of these studies are small in size and/or look at a single site, which further adds to the challenge. To date, our study is one of the largest studies attempting to answer the question on depth of 
invasion and it's correlation with occult nodal metastasis. Additionally, it is one of the only studies with adequate data to explore site-specific behaviors of tumors. It has long been understood that there are variations in the lymphatic patterns and lymphatic risk throughout the oral cavity, yielding certain sites to be a higher risk for nodal metastasis. However, there is little information on how this affects clinical outcomes. This paper identifies common oral cavity sites and results in various recommendations on when to consider offering a patient a neck dissection versus observation at a specific depth of invasion.

Following logistic regression confirming correlation between depth of invasion and lymph node positivity we analyzed our data using three separate methods with a focus on specific depths with a $20 \%$ positive rate, overall cut off of depths with $20 \%$ positive rate, and negative predictive values of $80 \%$. We expected that slightly different answers would result from these various analyses that could be combined into overall set of recommendations based on our data.

A number of important limitations to our specific study should be considered. First, it is retrospective in nature and suffers from all the normal limitations of this type of study. Pathology reports were accepted as written and no effort was made to review the findings in a more scientific fashion. The patient pool was also limited to those who underwent neck dissection. At our institution surgeons vary in recommending neck dissection for T1N0 patients based on depth of invasion of initial biopsy 
confirmed on frozen section for patients of shallower depths. The recommendation ranges from $2 \mathrm{~mm}$ or $3 \mathrm{~mm}$ depth of invasion in standard cases depending on the surgeon. Aging patients or those with significant comorbidities may be offered greater depth thresholds prior to dissection. Therefore patients who did not undergo neck dissection due to not reaching cut off recommendations were not included in this study. We used patients who received neck dissections to explore data estimating what the results would have been if "watch and wait" had been undertaken at the various depths, which is obviously not the same as comparing treatment outcomes with neck dissection vs. "watch and wait". Finally for purposes of this study we utilized $20 \%$ risk of occult metastasis as a threshold to recommend neck dissection. While this is the most standard recommendation, if a surgeon accepted a higher or lower rate, then our recommendations would not be applicable.

The utility of depth of invasion has been questioned due to a number of limitations what were not study specific per se but deserve mention and discussion. One of the critiques to using depth is biopsy-sampling error. Holmstrup et al ${ }^{16}$ reported on 101 lesions with initial biopsy followed by complete excision on average 10.4 months after biopsy. While the study compared histologic diagnosis and not depth of invasion only $49 \%$ of lesions matched raising questions regarding both the possibilities of sampling error and pathologist variability. At our institution we overcome this challenge by basing final decisions for neck dissection on patients with "close decisions" to frozen section pathology with multiple sampling where indicated. Thus we rely not only on the initial biopsy but information at the time of 
resection. In addition, in cases where depth of invasion is the decision maker, the attending surgeon views the frozen section slides with the pathologist as depth measurements are made. The limitations of this methodology are patient uncertainty prior operation of the final plan and allotment of OR time for patients who ultimately do not qualify for neck dissection. Despite these limitations this practice has been well received by patients and successful in assisting with final decisions with comprehensive and standardized reviews of specimens.

Another potential error in depth of invasion assessment may stem from known discrepancies of various sites in regards to mucosal shrinkage following resection which has been explored by a number of authors with variable discrepancies reported from the low $20 \%$ to a high upwards of $71.90 \% 17,18$. While again these studies do not directly assess the depth of invasion question they should be considered. One of the advantages of our study was the adequate sample size for sub-site analysis, which takes into consideration the variety of tissues in the oral cavity adding a level of credence to our study not available to many others.

Finally, a recent prospective clinical trial examined elective treatment of the neck versus therapeutic (watch and wait) demonstrating a statistically significant overall and disease free survival benefit in patients undergoing elective neck dissection. In this study, using logistic-regression in the elective group depth of invasion was the only factor that was significantly associated with node positivity for the 72 patients with positive nodes demonstrating a marked increase in cumulative lymph-node 
positivity with increasing depth of invasion from $3 \mathrm{~mm}(5.6 \%)$ to $4 \mathrm{~mm}(16.9 \%)$. Despite this finding the authors conclude that given lack of statistical significance the result was hypothesis generating at best. It should be noted that depth of invasion was not the primary endpoint of the study nor was the study powered to answer the question of depth of invasion. In addition since the study included both $\mathrm{T} 1$ and $\mathrm{T} 2$ patients it is not generalizable to the T1 only population for which depth of invasion is most commonly used as an indicator for treatment decisions; given the $\mathrm{T} 2$ and above patients receive elective neck dissection regardless of depth.

Despite the stated study specific and general limitations above we believe our data represents a significant contribution to the literature on the subject due to the large numbers, statistical validity of the findings and the fact that depth of invasion was the most statistically significant predictor of neck metastasis. While certainly this data is not adequate to base all clinical decisions it does provide a level of evidence that can guide surgeons as they treat individual patients particularly with clinical T1N0 disease. Table 9 summarizes the treatment recommendations based on the data of the study. Recommendations are based off of the descriptive data of $20 \%$ rates at various levels, $20 \%$ cutoff points considering all levels, and the negative predictive values of $80 \%$. We found that the tongue and floor of mouth were our highest risk sites and thus had a more aggressive approach to offering a neck dissection. If the primary lesion is on the tongue, then the data suggest neck dissection at $2 \mathrm{~mm}$ depth of invasion. At the floor of mouth, then $2-3 \mathrm{~mm}$ is the 
recommendation. The retromolar trigone, and alveolus/hard palate are slightly lower risk sites and with recommendations in the $3-4 \mathrm{~mm}$ range.

In analysis of our T1 lesions independently (table 8), we found that our data indicated $2 \mathrm{~mm}$ would be an appropriate threshold for offering a neck dissection to T1 patients. We noted that this number is influenced by the fact that a large percentage of our T1 lesions were primarily tongue and floor of mouth, thus influencing our data toward a more aggressive treatment regimen overall for these regions.

Table 9: Summary of pertinent findings at specific anatomic sites and recommendations for the appropriate depth to offer a neck dissection

\footnotetext{
Conclusion:

We conclude that depth of invasion remains an important variable to consider when making treatment recommendations to patients with clinical T1N0 disease. The recommendations should also take both depth and location of tumor into account. We have additionally suggested methods that help to diminish some of the limitation of this technique including standardization of depth measurements with surgeon and pathologist and frozen section analysis to diminish sampling error. We believe depth of invasion remains as an important factor to consider for future prospective studies.
} 


\section{Resources:}

1. American Cancer Society: Cancer Facts and Figures 2015. Atlanta: American Cancer Society; 2015.

2. Gourin CG, Conger BT, Porubsky ES, Sheils WC, Bilodeau PA, Coleman TA. The effect of occult nodal metastases on survival and regional control in patients with head and neck squamous cell carcinoma. Laryngoscope. 2008; 118(7):1191-4.

3. Pitman KT. Rationale for elective neck dissection. AM J Otolaryngol 2000;21(0196-0709;1):31-7.

4. Ahlberg A, Nikolaidis P, Engstrom T, et al. Morbidity of supraomohyoidal and modified radical neck dissection combined with radiotherapy for head and neck cancer: a prospective longitudinal study. Head Neck. 2012;34(1):66-72.

5. Bradley PJ, Ferlito A, Silver CE, Takes RP, Woolgar JA, Strojan P, et al. Neck treatment and shoulder morbidity: still a challeng. Head Neck 2010.

6. Weiss $\mathrm{MH}$, Harrison LB, Isaacs RS. Use of decision analysis in planning a management strategy for the stage N0 neck. Arch Otolaryngol Head Neck Surg 1994; 120(0886-4470;7):699-702.

7. Sparano A, Weinstein G, Chalian A, Yodul M, Weber R. Multivariate predictors of occult neck metastasis in early oral tongue cancer. Otolaryngol Head Neck Surg. 2004 Oct;131(4):472-6. 
8. Fakih AR, Rao RS, Borges AM, Patel AR. Elective versus therapeutic neck dissection in early carcinoma of the oral tongue. Am J Surg. 1989 Oct;158(4):309-13.

9. Ambrosch P1, Kron M, Fischer G, Brinck U. Micrometastases in carcinoma of the upper aerodigestive tract: detection, risk of metastasizing, and prognostic value of depth of invasion. Head Neck. 1995 Nov-Dec;17(6):473-9.

10. Fukano H, Matsuura H, Hasegawa Y, Nakamura S. Depth of invasion as a predictive factor for cervical lymph node metastasis in tongue carcinoma. Head Neck. 1997 May;19(3):205-10.

11. Tan WJ1, Chia CS, Tan HK, Soo KC, Iyer NG. Prognostic significance of invasion depth in oral tongue squamous cell carcinoma. ORL J Otorhinolaryngol Relat Spec. 2012;74(5):264-70. doi: 10.1159/000343796. Epub 2012 Nov 2.

12. Kane SV1, Gupta M, Kakade AC, D' Cruz A. Depth of invasion is the most significant histological predictor of subclinical cervical lymph node metastasis in early squamous carcinomas of the oral cavity. Eur J Surg Oncol. 2006 Sep;32(7):795-803. Epub 2006 Jun 13.

13. Melchers LJ, Schuuring E, van Dijk BA, de Bock GH, Witjes MJ, van der Laan $\mathrm{BF}$, van der Wal JE, Roodenburg JL. Tumour infiltration depth $\geq 4 \mathrm{~mm}$ is an indication for an elective neck dissection in pT1cN0 oral squamous cell carcinoma. Oral Oncol. 2012 Apr;48(4):337-42. doi:

10.1016/j.oraloncology.2011.11.007. Epub 2011 Nov 29. 
14. Warburton G1, Nikitakis NG, Roberson P, Marinos NJ, Wu T, Sauk JJ Jr, Ord RA, Wahl SM. Histopathological and lymphangiogenic parameters in relation to lymph node metastasis in early stage oral squamous cell carcinoma. J Oral Maxillofac Surg. 2007 Mar;65(3):475-84.

15. Chen YW1, Yu EH, Wu TH, Lo WL, Li WY, Kao SY. Histopathological factors affecting nodal metastasis in tongue cancer: analysis of 94 patients in Taiwan. Int J Oral Maxillofac Surg. 2008 Oct;37(10):912-6. doi:

10.1016/j.ijom.2008.07.014. Epub 2008 Sep 11.

16. Holmstrup P1, Vedtofte P, Reibel J, Stoltze K . Oral premalignant lesions: is a biopsy reliable? J Oral Pathol Med. 2007 May;36(5):262-6.

17. Mistry RC, Qureshi SS, Kumaran C: Post-resection mucosal margin shrinkage in oral cancer: Quantification and significance. J Surg Oncol 91:131, 2005

18. Cheng A, Cox D, Schmidt BL. Oral squamous cell carcinoma margin discrepancy after resection and pathologic processing. J Oral Maxillofac Surg. 2008 Mar;66(3):523-9.

19. D’Cruz AK, Vaish R, Kapre N, Dandekar M, et al. Elective versus Therapeutic Neck Dissection in Node-Negative Oral Cancer. N Engl J Med. 2015 Aug 6;373(6):521-9.

20. Shah JP, Candela FC, Poddar AK, et al The patterns of cervical lymph node metastasis from squamous carcinoma of the oral cavity. Cancer 1990;66(1)109-113. 
21. Ganly I, Patel S, Shah J. Early stage squamous cell cancer of the oral tongueclinicopathologic features affecting outcome. Cancer. 2012 Jan 1; 118(1):10111.

22. Pimenta Aaral TM, Da Silva Freire AR, Carvalho AL, Pinto CA, Kowalski LP. Predictive factors of occult metastasis and prognosis of clinical stages I and II squamous cell carcinoma of the tongue and floor of mouth. Oral Oncol. 2004. Spe;40(8):780-6

23. Kligerman J, Lima RA, Soares JR, Prado L, Dias FL, Freitas EQ, Olivatto LO. Supraomohyoid neck dissection in the treatment of T1/T2 squamous cell carcinoma of oral cavity. Am J Surg. 1994 Nov: 168(5):391-4.

24. Huang SH. Hwang D, Lockwood G, Goldstein DP, O'Sullivan B. Predictive value of tumor thickness for cervical lymph-node involvement in squamous cell carcinoma of the oral cavity: a meta-analysis of reported studies. Cancer, 2009 Apr 1; 115(7)1489-97

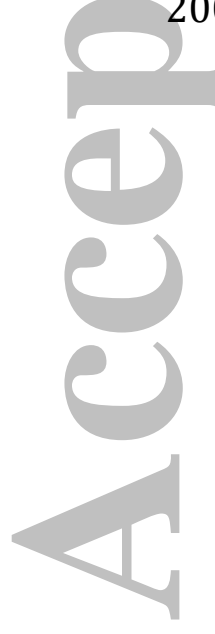

John Wiley \& Sons, Inc. 
Table 1: Pathologic staging (No. of patients=286)

\begin{tabular}{|cccc|}
\hline Overall Stage & TNM & Number of patients & Overall Percentage \\
\hline $\mathbf{1}$ & T1N0M0 & $66(23.1 \%)$ & $23.1 \%$ \\
\hline $\mathbf{2}$ & T2N0M0 & $54(18.9 \%)$ & $18.9 \%$ \\
\hline 3 & T1N1M0 & $16(5.6 \%)$ & \\
& T2N1M0 & $17(5.9 \%)$ & $13.5 \%$ \\
\hline & T3N0M0 & $5(1.7 \%)$ & \\
& T3N1M0 & $1(0.3 \%)$ & \\
& T1N2M0 & $8(2.8 \%)$ & $44.3 \%$ \\
& T2N2M0 & $24(8.4 \%)$ & \\
\hline & T3N2M0 & $5(1.7 \%)$ & \\
& T4N0M0 & $47(16.4 \%)$ & \\
& T4N1M0 & $9(3.1 \%)$ & \\
\hline
\end{tabular}

John Wiley \& Sons, Inc.

This article is protected by copyright. All rights reserved. 
Table 2: Percentage of necks with positive nodes measured at $1 \mathrm{~mm}$ increments of depth of invasion

\begin{tabular}{|c|c|c|c|}
\hline Depth of Invasion & $\begin{array}{c}\text { Number of necks } \\
\text { with NEGATIVE } \\
\text { nodes (N=223) }\end{array}$ & $\begin{array}{c}\text { Number of Necks } \\
\text { with POSITIVE } \\
\text { nodes (N=167) }\end{array}$ & $\begin{array}{c}\text { Percentage of } \\
\text { necks with } \\
\text { PoSITIVE nodes }\end{array}$ \\
\hline $1 \mathrm{~mm}$ & 7 & 0 & $0 \%$ \\
\hline $\mathbf{2 m m}$ & $\mathbf{1 2}$ & $\mathbf{3}$ & $\mathbf{2 0 \%}$ \\
\hline $3 \mathrm{~mm}$ & 23 & 7 & $23 \%$ \\
\hline $4 \mathrm{~mm}$ & 25 & 9 & $26 \%$ \\
\hline $5 \mathrm{~mm}$ & 22 & 6 & $21 \%$ \\
\hline $6 \mathrm{~mm}$ & 11 & 5 & $31 \%$ \\
\hline $7 \mathrm{~mm}$ & 7 & 5 & $42 \%$ \\
\hline $8 \mathrm{~mm}$ & 14 & 7 & $33 \%$ \\
\hline $9 \mathrm{~mm}$ & 14 & 12 & $46 \%$ \\
\hline $10 \mathrm{~mm}$ & 12 & 13 & $52 \%$ \\
\hline$>10 \mathrm{~mm}$ & 76 & 100 & $57 \%$ \\
\hline
\end{tabular}

Bold + Shading: Shows the shallowest depth of invasion (in millimeters) where $20 \%$ or greater of the necks dissected demonstrated postive lymph nodes

-Each neck was treated independently 
Table 3: Various anatomical sites showing the shallowest depth of invasion where at least $20 \%$ of the necks had positive lymph nodes

\begin{tabular}{|c|c|}
\hline Anatomical site & Depth of invasion \\
\hline Tongue & $2 \mathrm{~mm}$ \\
\hline Floor of mouth (FOM) & $3 \mathrm{~mm}$ \\
\hline Retromolar trigone & $3 \mathrm{~mm}$ \\
\hline Alveolus/hard palate (HP) & $4 \mathrm{~mm}$ \\
\hline
\end{tabular}

John Wiley \& Sons, Inc.

This article is protected by copyright. All rights reserved. 
Table 4: $20 \%$ cutoff points where $20 \%$ of all necks at that depth and shallower would present with positive nodes

\begin{tabular}{|c|c|c|c|}
\hline $\begin{array}{c}\text { Depth of } \\
\text { Invasion }\end{array}$ & $\begin{array}{c}\text { Number of necks } \\
\text { with NEGATIVE } \\
\text { nodes (N=223) }\end{array}$ & $\begin{array}{c}\text { Number of Necks } \\
\text { with POSITIVE } \\
\text { nodes (N=167) }\end{array}$ & $\begin{array}{c}\text { Percentage of } \\
\text { necks with } \\
\text { PoSITIVE nodes }\end{array}$ \\
\hline $1 \mathrm{~mm}$ & 7 & 0 & $0 \%$ \\
\hline $2 \mathrm{~mm}$ & 12 & 3 & $14 \%$ \\
\hline $3 \mathrm{~mm}$ & 23 & 7 & $19 \%$ \\
\hline $\mathbf{4 m m}$ & $\mathbf{2 5}$ & $\mathbf{9}$ & $\mathbf{2 2 \%}$ \\
\hline $5 \mathrm{~mm}$ & 22 & 6 & $22 \%$ \\
\hline $6 \mathrm{~mm}$ & 11 & 5 & $22 \%$ \\
\hline $7 \mathrm{~mm}$ & 7 & 5 & $24 \%$ \\
\hline $8 \mathrm{~mm}$ & 14 & 7 & $25 \%$ \\
\hline $9 \mathrm{~mm}$ & 14 & 12 & $28 \%$ \\
\hline $10 \mathrm{~mm}$ & 12 & 13 & $30 \%$ \\
\hline$>10 \mathrm{~mm}$ & 76 & 100 & $42 \%$ \\
\hline
\end{tabular}

Bold + Shading: Indicates the $20 \%$ cuoff point. This is the level (in millimeters) where $20 \%$ of all the necks at that depth and shallower demonstrated positive lymph nodes. 
Table 5: 20\% cutoff points for various anatomical sites with $95 \%$ confidence intervals among all sites

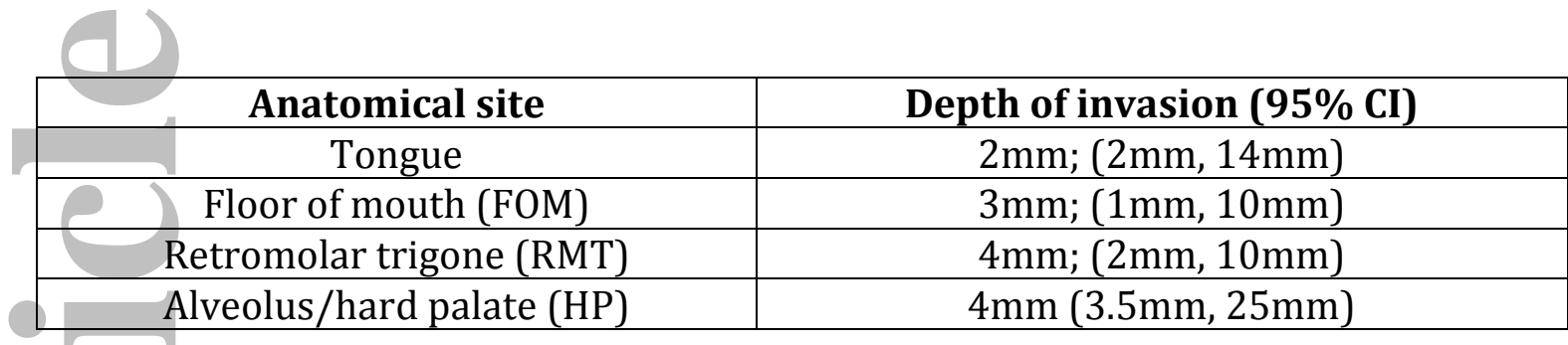

$\mathrm{CI}=$ Confidence interval
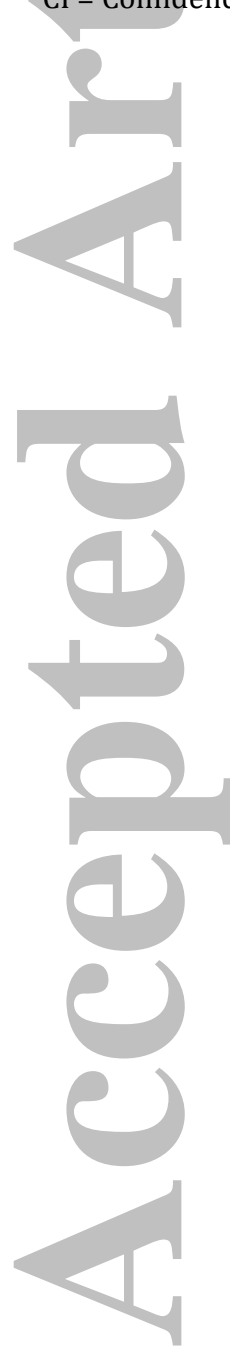

John Wiley \& Sons, Inc.

This article is protected by copyright. All rights reserved. 
Table 6: Diagnostic operating characteristics of depth of invasion ( $\mathrm{mm}$ ) for predicting nodal involvement

\begin{tabular}{|c|c|c|c|c|c|}
\hline $\begin{array}{l}\text { Tumor } \\
\text { Depth }\end{array}$ & $\begin{array}{c}\text { Sensitivity } \\
(95 \% \mathrm{Cl})\end{array}$ & $\begin{array}{c}\text { Specificity } \\
\text { (95\% CI) }\end{array}$ & $\begin{array}{c}\text { PPV } \\
(95 \% \text { Cl) }\end{array}$ & $\begin{array}{c}\text { NPV } \\
(95 \% \text { Cl) }\end{array}$ & $\begin{array}{c}\text { AUC } \\
(95 \% \mathrm{Cl})\end{array}$ \\
\hline $1 \mathrm{~mm}$ & $\begin{array}{c}100 \% \\
\mathrm{n} / \mathrm{a}\end{array}$ & $\begin{array}{c}3 \% \\
(0 \%, 6 \%)\end{array}$ & $\begin{array}{c}41 \% \\
(35 \%, 47 \%)\end{array}$ & $\begin{array}{c}100 \% \\
n / a\end{array}$ & \multirow{6}{*}{$\begin{array}{c}0.68 \\
(0.61,0.74)\end{array}$} \\
\hline $2 \mathrm{~mm}$ & $\begin{array}{c}98 \% \\
(95 \%, 100 \%)\end{array}$ & $\begin{array}{c}9 \% \\
(5 \%, 13 \%)\end{array}$ & $\begin{array}{c}42 \% \\
(36 \%, 48 \%)\end{array}$ & $\begin{array}{c}89 \% \\
(75 \%, 100 \%)\end{array}$ & \\
\hline $3 \mathrm{~mm}$ & $\begin{array}{c}94 \% \\
(90 \%, 98 \%)\end{array}$ & $\begin{array}{c}21 \% \\
(15 \%, 27 \%)\end{array}$ & $\begin{array}{c}44 \% \\
(38 \%, 50 \%)\end{array}$ & $\begin{array}{c}84 \% \\
(73 \%, 95 \%)\end{array}$ & \\
\hline $4 \mathrm{~mm}$ & $\begin{array}{c}88 \% \\
(82 \%, 94 \%) \\
\end{array}$ & $\begin{array}{c}33 \% \\
(26 \%, 40 \%) \\
\end{array}$ & $\begin{array}{c}47 \% \\
(40 \%, 54 \%)\end{array}$ & $\begin{array}{c}80 \% \\
(71 \%, 89 \%) \\
\end{array}$ & \\
\hline $5 \mathrm{~mm}$ & $\begin{array}{c}83 \% \\
(76 \%, 90 \%) \\
\end{array}$ & $\begin{array}{c}43 \% \\
(36 \%, 50 \%) \\
\end{array}$ & $\begin{array}{c}50 \% \\
(43 \%, 57 \%) \\
\end{array}$ & $\begin{array}{c}80 \% \\
(72 \%, 88 \%) \\
\end{array}$ & \\
\hline $6 \mathrm{~mm}$ & $\begin{array}{c}81 \% \\
(74 \%, 88 \%)\end{array}$ & $\begin{array}{c}48 \% \\
(41 \%, 55 \%)\end{array}$ & $\begin{array}{c}51 \% \\
(44 \%, 58 \%)\end{array}$ & $\begin{array}{c}79 \% \\
(71 \%, 87 \%)\end{array}$ & \\
\hline
\end{tabular}

PPV= Positive predictive value; NPV=Negative predictive value; $\mathrm{AUC}=$ Area under curve; $\mathrm{Cl}=$ Confidence interval

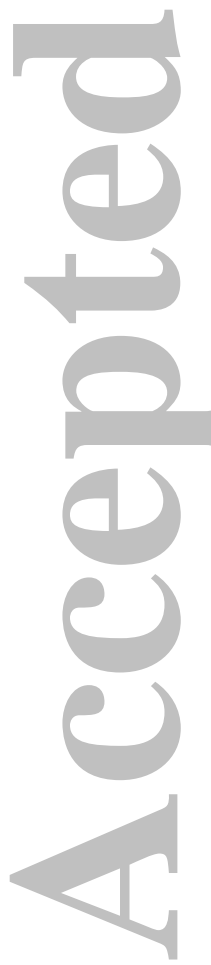

John Wiley ${ }^{1}$ \& Sons, Inc.

This article is protected by copyright. All rights reserved. 
Table 7: Negative predictive values (NPV) at various anatomical sites predicting a $20 \%$ nodal involvement

\begin{tabular}{|c|c|}
\hline Anatomical site & NPV \\
\hline Tongue & $2 \mathrm{~mm}$ \\
\hline Floor of mouth (FOM) & $2 \mathrm{~mm}$ \\
\hline Retromolar trigone (RMT) & $3 \mathrm{~mm}$ \\
\hline Alveolus/hard palate (HP) & $3 \mathrm{~mm}$ \\
\hline
\end{tabular}

$\mathrm{NPV}=$ Negative predictive value
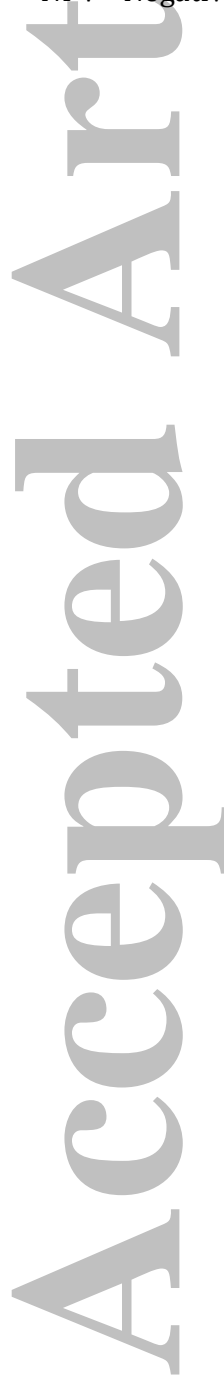

John Wiley \& Sons, Inc.

This article is protected by copyright. All rights reserved. 
Table 8: T1 Lesions (No. of necks=111)

\begin{tabular}{|c|c|c|c|c|c|c|c|}
\hline $\begin{array}{c}\text { Depth of } \\
\text { Invasion }\end{array}$ & $\begin{array}{c}\text { Number of } \\
\text { Necks with } \\
\text { NEGATIVE } \\
\text { nodes }\end{array}$ & $\begin{array}{c}\text { Number of } \\
\text { Necks with } \\
\text { POSITIVE } \\
\text { nodes }\end{array}$ & $\begin{array}{c}\text { Percentage } \\
\text { of necks } \\
\text { with } \\
\text { POSITIVE } \\
\text { nodes }\end{array}$ & Sensitivity & Specificity & PPV & NPV \\
\hline $1 \mathrm{~mm}$ & 5 & 0 & $0 \%$ & $100 \%$ & $6 \%$ & $31 \%$ & $100 \%$ \\
\hline $2 \mathrm{~mm}$ & 7 & 3 & $\mathbf{3 0 \%}$ & $91 \%$ & $15 \%$ & $31 \%$ & $\mathbf{8 0 \%}$ \\
\hline $3 \mathrm{~mm}$ & 16 & 5 & $24 \%$ & $76 \%$ & $36 \%$ & $33 \%$ & $78 \%$ \\
\hline $4 \mathrm{~mm}$ & 17 & 3 & $15 \%$ & $67 \%$ & $58 \%$ & $40 \%$ & $80 \%$ \\
\hline $5 \mathrm{~mm}$ & 13 & 3 & $19 \%$ & $57 \%$ & $74 \%$ & $48 \%$ & $81 \%$ \\
\hline $6 \mathrm{~mm}$ & 5 & 2 & $29 \%$ & $51 \%$ & $81 \%$ & $53 \%$ & $80 \%$ \\
\hline $7 \mathrm{~mm}$ & 3 & 4 & $57 \%$ & $39 \%$ & $85 \%$ & $52 \%$ & $78 \%$ \\
\hline $8 \mathrm{~mm}$ & 5 & 4 & $44 \%$ & $27 \%$ & $91 \%$ & $56 \%$ & $75 \%$ \\
\hline $9 \mathrm{~mm}$ & 4 & 1 & $20 \%$ & $24 \%$ & $96 \%$ & $73 \%$ & $75 \%$ \\
\hline $10 \mathrm{~mm}$ & 2 & 2 & $50 \%$ & $18 \%$ & $99 \%$ & $86 \%$ & $74 \%$ \\
\hline$>10 \mathrm{~mm}$ & 1 & 6 & $86 \%$ & 0 & $100 \%$ & $\mathrm{n} / \mathrm{a}$ & $70 \%$ \\
\hline
\end{tabular}

$\mathrm{PPV}=$ Positive predictive value

$\mathrm{NPV}=$ Negative predictive value

Bold + Shading: Shows the shallowest depth of invasion (in millimeters) where $20 \%$ or greater of the necks dissected demonstrate postive lymph nodes and the $\mathrm{NPV}$ is $80 \%$ or less. 
Table 9: Summary of pertinent findings at specific anatomic sites and recommendations for the appropriate depth to offer a neck dissection

\begin{tabular}{|c|c|c|c|c|}
\hline$\underline{\text { Site }}$ & $\frac{\text { Descriptive }}{\text { Data }}$ & $\begin{array}{l}\underline{20 \%} \\
\text { cutoff }\end{array}$ & NPV & $\begin{array}{l}\text { Recommendation } \\
\text { for neck dissection }\end{array}$ \\
\hline Tongue & $2 \mathrm{~mm}$ & $2 \mathrm{~mm}$ & $2 \mathrm{~mm}$ & $2 \mathrm{~mm}$ \\
\hline FOM & $3 \mathrm{~mm}$ & $3 \mathrm{~mm}$ & $2 \mathrm{~mm}$ & $2-3 \mathrm{~mm}$ \\
\hline RMT & $3 \mathrm{~mm}$ & $4 \mathrm{~mm}$ & $3 \mathrm{~mm}$ & $3-4 \mathrm{~mm}$ \\
\hline Alveolus/HP & $4 \mathrm{~mm}$ & $4 \mathrm{~mm}$ & $3 \mathrm{~mm}$ & $3-4 \mathrm{~mm}$ \\
\hline All sites & $2 \mathrm{~mm}$ & $4 \mathrm{~mm}$ & $4 \mathrm{~mm}$ & $2-4 \mathrm{~mm}$ \\
\hline
\end{tabular}

Descriptive data: precise value for the depth of invasion where the percentage of necks with positive nodes measured at $1 \mathrm{~mm}$ increments reached a value of $20 \%$.

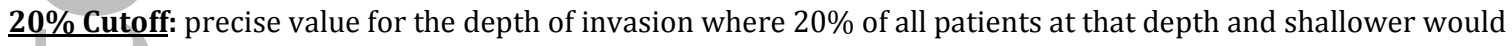
present with positive lymph nodes.

NPV: Negative predictive value represents the depth of invasion in a patient whom if a neck dissection was not performed, would truly be negative for disease.

Recommendation: given all data collected, we are recommending a neck dissection at this depth 